\title{
Reply to the Letter by A. Abbott Regarding "Asymptomatic Carotid Stenosis-More Misunderstandings in the Expectation of a Surgical Benefit"
}

\author{
Margaret H. Walkup • Peter L. Faries
}

Published online: 20 April 2011

(C) Springer Science+Business Media, LLC 2011

To the Editor:

Dr. Abbott has raised several very interesting issues. It is important to note that rather than errors, the subjects Dr. Abbott highlights are the interpretations of data as reported in the original studies. Our interpretation agrees with that of the authors of the original manuscripts. Recommendation guidelines from both the American Heart Association as well as the Society for Vascular Surgery support intervention to correct asymptomatic carotid stenosis $>80 \%$ for patients in whom a $<3 \%$ perioperative aggregate stroke/death rate can be achieved. This is based on level I evidence accrued in numerous randomized controlled trials. No level I or level II evidence exists to support observation and medical management of these patients. We would welcome a randomized, prospective trial to assess whether any improvement in the natural history of asymptomatic carotid stenosis can be achieved with current medical therapy. And, it is our sincere hope that medical therapy can progress the point at which intervention for carotid stenosis is no longer required (especially as we begin to age).

We apologize for the typo in the introduction of our paper when we stated that the ACAS trial "....randomized over 4,500 patients with asymptomatic carotid stenosis..." This should have read that the ACAS trial had over 4,500 patient-years of observation for patients with asymptomatic carotid stenosis.

Thank you,
M. H. Walkup · P. L. Faries $(\bowtie)$

Division of Vascular Surgery,

5 East 98th Street, 4th Floor, Box 1273,

New York, NY 10029, USA

e-mail: peter.faries@mssm.edu 